\title{
The Value of MRI Brain DWI (ADC) in the Management of Ventriculomegaly in Pediatric Age Group
}

\author{
MONA M.M. FATOUH, M.Sc.*; HASSAN A.H. EL-KIKI, M.D.*; MERVAT Sh. EL-SAHRAGTY, M.D.*; \\ HASSAN I. EL-SHAFEI, M.D.** and TALAAT A. HASSAN, M.D.* \\ The Departments of Radiology* and Neurosurgery**, Faculty of Medicine, Cairo University, Egypt
}

\begin{abstract}
Background: Neurosurgeons need to answer the question: Which infant with an enlarged ventricular system needs neurosurgical intervention (progressive pressure hydrocephalus) and which one needs to be left alone and diagnosis of compensated pressure hydrocephalus is established using MRI brain DWI (ADC) as well as a useful follow-up tool for the treatment success.

Aim of the Work: Investigate the role of ADC's value in children with hydrocephalus to differentiate between compensated and progressive hydrocephalus and follow-up after neurosurgical interventions.
\end{abstract}

Patients and Methods: This prospective study included (40 participants) 10 controls ( 5 males and 5 females) and 30 patients (18 males and 12 females). All the patients underwent routine MRI brain and DWI (ADC) examinations.

Results: In our study, we found that DWI (ADC) is a useful non invasive tool in diagnosis and follow-up the treatment success in hydrocephalic children, providing us the mean ADC cut off value (1.0817) for differentiation (compensated from progressive pressure).

Conclusion: Elevated ADC values in children with progressive hydrocephalus and normalization of the previously high mean ADC value associated with successful neurosurgical intervention, however some patients can present with borderline ADC values and diagnosis of PPH based on the clinical background of the patient and follow-ups. The patients with compensated pressure hydrocephalus, there is no significant decrease of the calculated mean ADC value with follow-ups.

Key Words: Compensated pressure hydrocephalus - Progressive pressure hydrocephalus - MRI-DWI-ADC.

\section{Introduction}

DIFFUSION imaging proved useful in the initial assessment and in the post-treatment monitoring

Correspondence to: Dr. Mona M.M. Fatouh, The Department of Radiology, Faculty of Medicine, Cairo University, Egypt of patients with hydrocephalus. Variation in ADC value before and after treatment reflects the extent of subependymal absorption of CSF. Regardless of the initial values, successful treatment resulted in nearly normalization of the ADC value [1]

The absence of interstitial edema can help to differentiate between compensated and progressive hydrocephalus thus facilitating the decision to withhold CSF diversion in an infant with a compensated hydrocephalus [2]

The increased ADC values in infants with progressive hydrocephalus are probably caused by an increase of the extracellular water compartment. This phenomenon is explained by transependymal CSF absorption and stasis of extracellular fluid flow [3].

The ventricular dilatation and PVH are not reliable signs in assessing hydrocephalus treatment concluding that ADC value measurement and normalization of subarachnoid spaces are reliable signs for treatment assessment [6].

\section{Patients and Methods}

This study was performed on 40 participants at Kasr Al-Ainy Cairo University during period between December 2014 and January 2016; 10 control (5 males and 5 females) and 30 patients (18 males and 12 females).

All patients were referred to the Diagnostic Radiology Department from Neurosurgery Outpatient Clinic.

Patients were divided according to their clinical presentation into two groups, suspected to have 
Progressive Pressure Hydro cephalous (PPH) and Compensated Pressure Hydro cephalous (CPH).

\section{Inclusion criteria:}

Patients had previous neuroimaging (U/S,CT and/or MRI) of ventriculomegaly.

\section{Exclusion criteria:}

- Patients with the combination of hydrocephalus and intra-parenchymal lesions, such as an intra cerebral tumour, were excluded.

- Patients with ex vacuo ventricular dilation by neuroimaging.

- Any contraindication for MRI: Anaesthesia or sedation complications (young children need complete sedation for performing MRI examinations).

All cases $(n=40 / 40)$ were subjected to routine Magnetic Resonance Imaging (MRI) of the brain (axial T1 WI, T2 WI and T2 FLAIR. sagittal T2WI) with DWI to calculate the mean ADC value.

\section{Diffusion technique:}

All subjects underwent Magnetic Resonance Imaging (MRI) on a 1.5-T scanner (Philips-Intera) by using $b$ values $0 \& 1000 \mathrm{sec} / \mathrm{mm}^{2}$, repetition time $(\mathrm{TR}) \geq 1880 \mathrm{msec}$, echo time $(\mathrm{TE})=70 \mathrm{msec}$, number of excitations (NEX) $=3$, matrix $256 \times 256$ with a field of view as small as possible, slice thickness 7-8mm, slice gap 1-2mm, scan time 3$4 \mathrm{~min}$.

\section{Post processing:}

The mean ADC values were calculated in the following manually selected Regions of Interest (ROI's) (one hemisphere): 1- Occipital grey matter 2- Peri ventricular white matter next to the occipital horn of the lateral ventricle 3- Thalamus 4- Peri ventricular white matter next to the frontal horn of the lateral ventricle 5- Frontal grey matter, according to Leliefeld et al., [2] technique.

\section{Interpretation:}

\section{In normal children:}

The calculated mean ADC value of $1075 \mathrm{~mm}^{2} / \mathrm{s}$ in the control subjects [4].

In our study we used mean ADC value 1075 $\mathrm{mm}^{2} / \mathrm{sec}$ (Forbes et al., [4]) as cut off value above which progressive pressure hydrocephalus was diagnosed.

\section{Results}

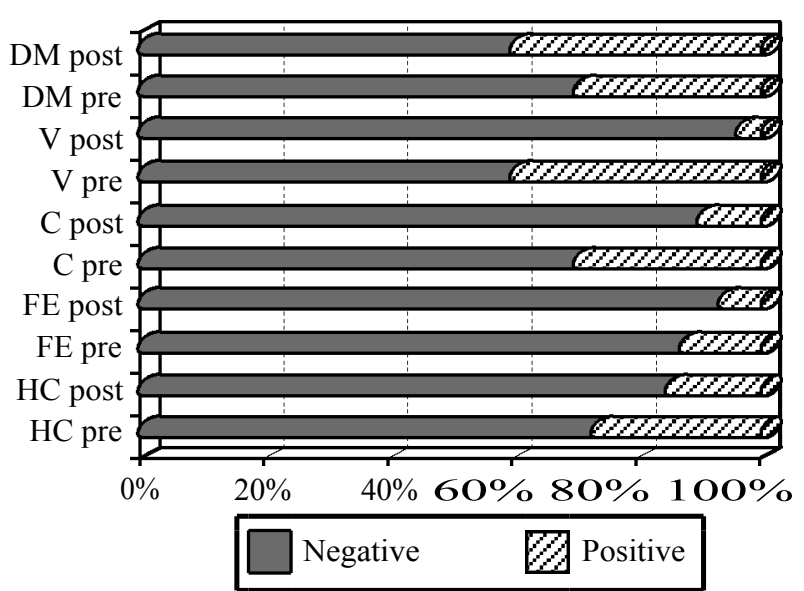

Chart (1): Columns chart showing clinical presentations percentages of ICP in the study group pre and post.

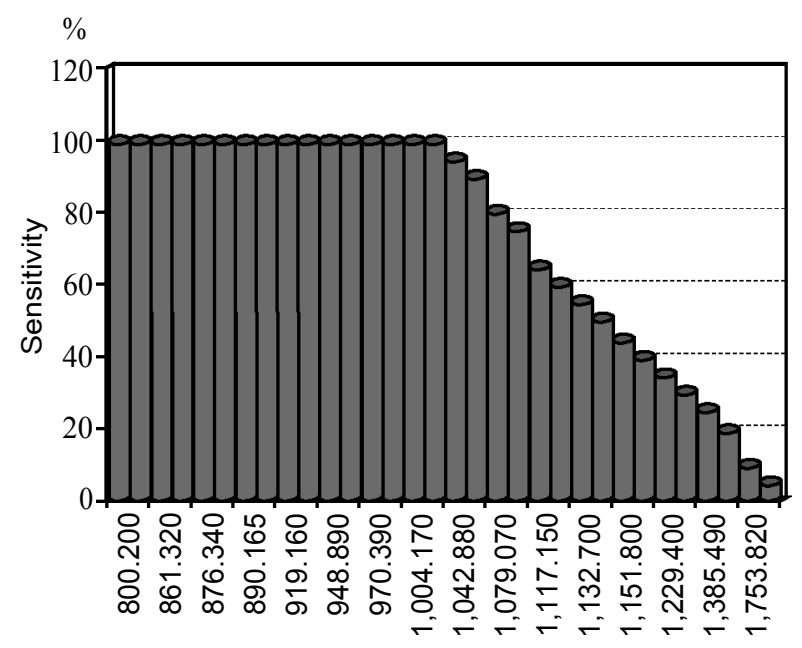

Mean ADC value $\mathrm{mm}^{2} / \mathrm{sec}$

Chart (2): Column chart demonstrate each mean ADC value in $\mathrm{mm} / \mathrm{sec}$ and its sensitivity by percentage.

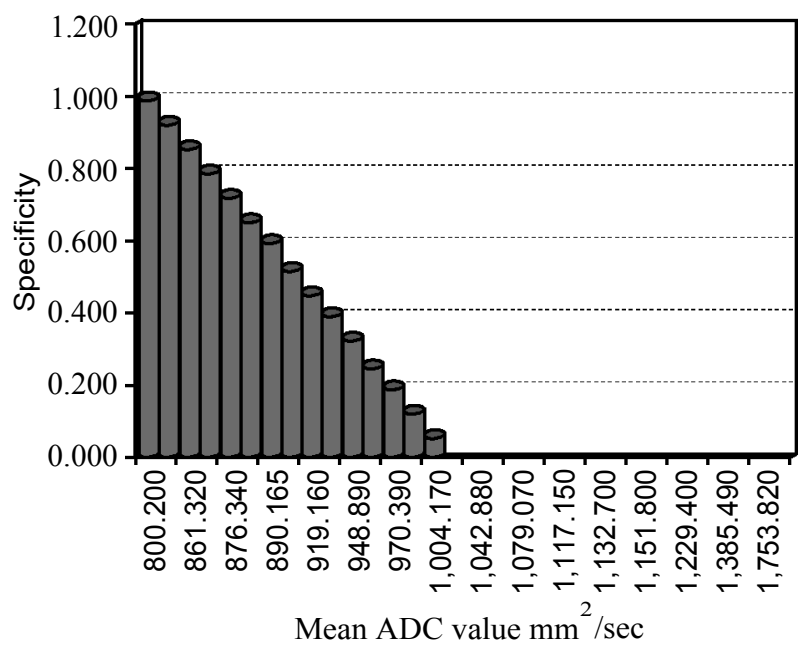

Chart (3): Column chart demonstrate each mean ADC value in $\mathrm{mm}^{2} / \mathrm{sec}$ and its specificity by percentage. 

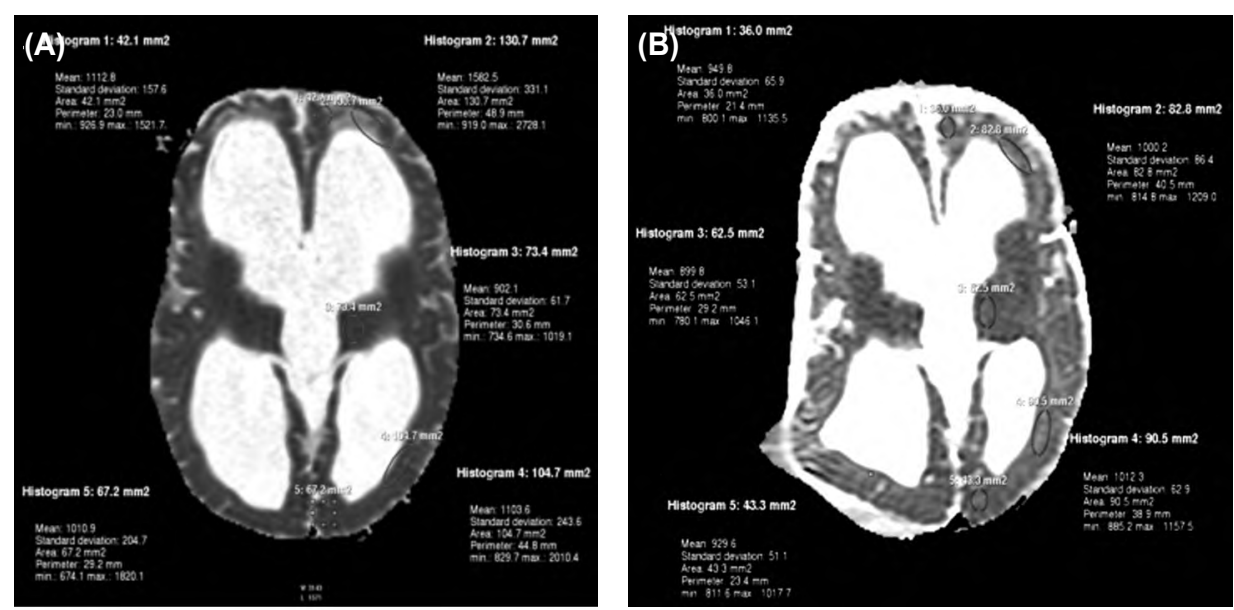

Fig. (1): Pre and post-operative ADC images of the 5 month old patient (PPH) showing improvement of the mean ADC value $958.34 \mathrm{~mm}^{2} / \mathrm{s}$ compared to pre-operative $1142.38 \mathrm{~mm}^{2} / \mathrm{s}$.
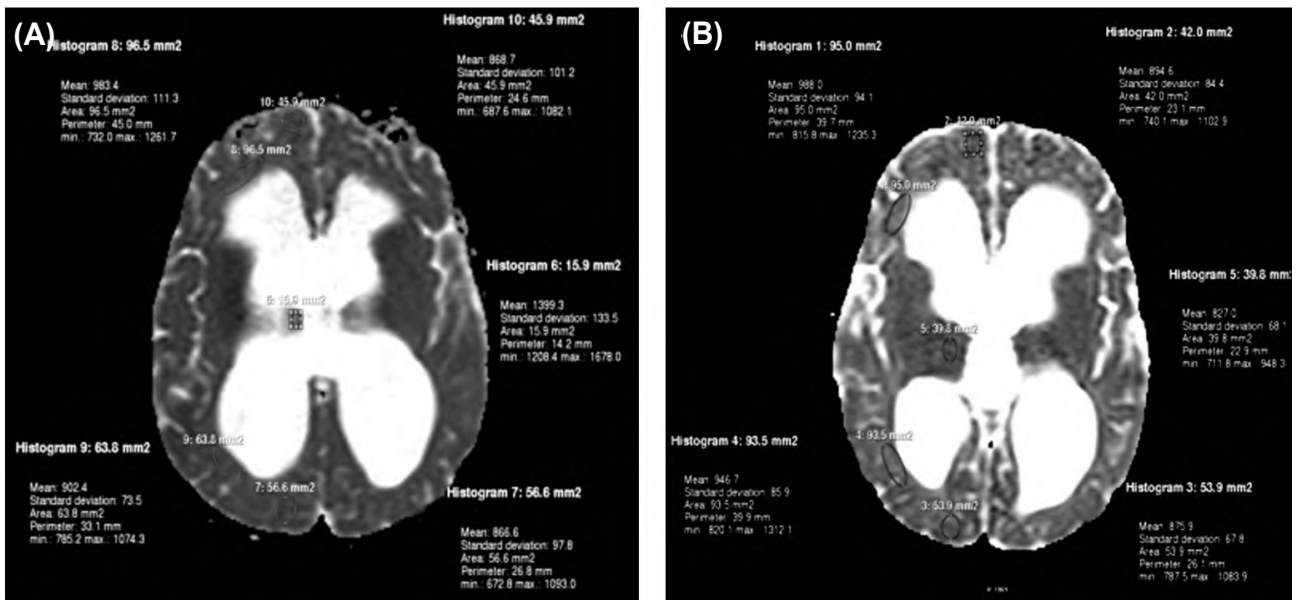

Fig. (2): ADC image of 1 year old female (CPH) showing normal mean ADC value $1004.08 \mathrm{~mm}^{2} / \mathrm{s}^{\text {and }}$ mean ADC value $906.44 \mathrm{~mm}^{2} / \mathrm{s}$ (4 months later).

Table (1): An overview of the calculated parameters (mean $\&$ SD) pre and post in study group.

\begin{tabular}{lcc}
\hline Group & MA/pre & MA/post \\
\hline Controls: & & \\
$\quad$ Mean & 920.388 & \\
Std. deviation & 105.1297 & \\
Compensated HC: & & \\
$\quad$ Mean & 916.138 & 875.7013 \\
Std. deviation & 58.6920 & 76.62554 \\
Progressive HC: & & \\
Mean & $1,201.987$ & 987.3020 \\
Std. deviation & 188.8273 & 49.13593 \\
\hline Total: & & \\
Mean & $1,024.394$ & 931.5017 \\
Std. deviation & 189.7318 & 84.97701 \\
\hline Mean ADC value & Sensitivity & Specificity \\
\hline $1,018.630$ & $100 \%$ & $100 \%$ \\
\hline
\end{tabular}

- The $p$-value (0.001) found to be of statistical significance (less than 0.05).
Statistical analysis:

Data were statistically described in terms of mean \pm Standard Deviation $( \pm$ SD), median and range, or frequencies (number of cases) and percentages when appropriate. Comparison of numerical variables between the study groups was done using Kruskal Wallis test with posthoc multiple 2group comparisons. Within group comparison of numerical variables was done using Wilcoxon signed rank test for paired (matched) samples. For comparing categorical data, Chi square $\left(\chi^{2}\right)$ test was performed. Exact test was used instead when the expected frequency is less than 5. Accuracy was represented using the terms sensitivity, and specificity. Receiver Operator Characteristic (ROC) analysis was used to determine the optimum cut off value for the studied diagnostic markers. $p$ values less than 0.05 was considered statistically significant. All statistical calculations were done using computer program SPSS (Statistical Package for the Social Science; SPSS Inc., Chicago, IL, USA) release 15 for Microsoft Windows (2006). 


\section{Discussion}

Our study revealed that ventricular dilatation was not decreased after successful treatment in all patients $(\mathrm{PPH})$ with improved clinical profile after treatment, these findings matches with Mori $\mathrm{K}$ et al., [5] about the ineffectiveness of using ventricular size in evaluation of hydrocephalus treatment.

Ulug et al., [6] documented that ventricular dilatation and $\mathrm{PVH}$ are not reliable signs in assessing hydrocephalus treatment concluding that ADC value measurement and normalization of subarachnoid spaces are reliable signs for treatment assessment which matched with our study.

In our study we used similar technique as showed by Leliefeld et al., [2], apart from we used $2 \mathrm{~b}$-values 0,1000 instead of $8 \mathrm{~b}$ values to decrease time of examination.

In our study we measured the ADC values at one cerebral hemispheres instead of both cerebral hemispheres as Leliefeld et al., [2] showed that $A D C$ values in the left and right sided ROI's were compared using a paired Student's $t$-Test and no significant difference between left and right sided $A D C$ values was found, left and right sided ADC values were averaged for each of the examined areas.

Forcebs et al found the control subjects with mean ADC value of $1075 \mathrm{~mm}^{2} / \mathrm{sec}$ [4]

In our study we found that mean ADC in control group (10 cases) $920.388 \mathrm{~mm}^{2} / \mathrm{sec} \pm 105.1297$.

Leliefeld et al., [2] showed a rapid and more extensive decrease in ADC values after CSF diversion than is to be expected with regard to physiological ADC decrease due to ageing alone. The pre-operative ADC increase can be explained by interstitial edema caused by transependymal CSF leakage or by vasogenic edema caused by capillary compression and stretching of the brain parenchyma. These findings may help to detect patients at risk of cerebral damage thus differentiating between progressive and compensated hydrocephalus.

In our study we found that mean ADC in all 15 patients with $\mathrm{PPH}$ was high and normalized after shunt with mean ADC value pre $1201.987 \mathrm{~mm}^{2} / \mathrm{sec}$ \pm 188.8273 and post $987.3020 \pm 49.13593$. These results similar to the study confronted by Leliefeld et al., [2] (mean pre ADC value $1196 \mathrm{~mm}^{2} / \mathrm{sec} \pm 136$ and post $924 \pm 73$.

Leliefeld et al., [2] showed that in infants with hydrocephalus low ADC values as measured with MR, are associated with a compensated hydrocephalus and may support a conservative approach with respect to the decision whether or not to shunt.

In our study we found that mean ADC in all 15 patients with $\mathrm{CPH}$ was normal with mean ADC value pre $916.138 \mathrm{~mm}^{2} / \mathrm{sec} \pm 58.6920$ and post $875.7013 \mathrm{~mm}^{2} / \mathrm{sec} \pm 76.62554$. These results similar to the study confronted by Leliefeld et al., [2] (mean pre ADC value $890.0 \mathrm{~mm}^{2} / \mathrm{sec}$ ).

\section{Conclusion:}

Elevated apparent diffusion coefficient values in children with progressive hydrocephalus with normalization of the previously high mean ADC value successful neurosurgical intervention, however some patients can present with borderline ADC values and diagnosis of PPH based on the clinical background of the patient and on the other hand confirmed radiological by TCD (RI) and MRA (TCBF). The patients with compensated pressure hydrocephalus, no significant decrease of the calculated mean ADC value with follow-up.

\section{References}

1- GULNUR ERDEMA, ONDER CELIKB, SEYMA HASCALIKB, et al.: Diffusion weighted imaging evaluation of stubble cerebral microstructural changes in intra uterine fetal hydrcephalus. Volume 25, Issue 10: P 1417-22, 2007.

2- LELIEFELD P.H., GOOSKENS R.H., BRAUN K.P., RAMOS L.M., UITERWAAL C.S., et al.: Diffusion weighted magnetic resonance imaging in term preterm brain injury: A comparison with site of lesion and lime from birth, Paediatrics, E114: P1004-14, 2009.

3- COUNSELL S.J., ALLSOP J.M., HARRISON M.C., LARKMAN D.J., KENNEA N.L., et al.: Diffusionweighted imaging of the brain in preterm infants with focal and diffuse white matter abnormality, Peditatrics, (E112): P1-7, 2003.

4- FORBES K.P., PIPE J.G. and BIRD C.R.: Changes in brain water diffusion during the 1 st year of life. Radiology; 222: 405-9, 2012.

5- MORI K., HANDA T., MURATA T. and NAKANO Y. Periventricular Lucency in CT of hydrocephalus and cerebral atrophy, J. Comput. Assist. Tomogr., E4: P2049, 2001.

6- ULUG, THUY N., TRUONG, CHRISTOPHER G., FILIPPI, et al.: Diffusion Imaging in Obstructive Hydrocephalus. A. J. N. R. Am. J. Neuroradiol., E 24: P1171-6, 2013. 


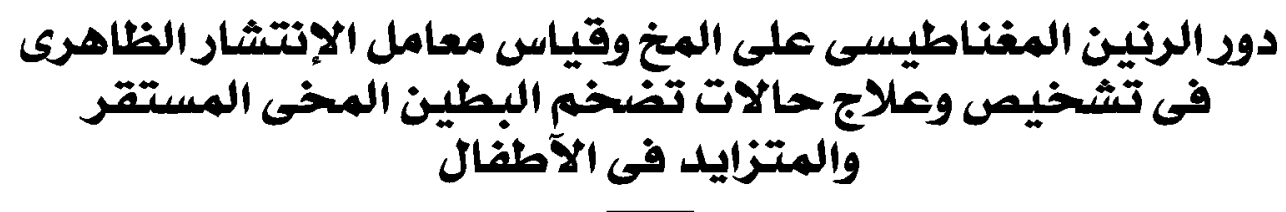

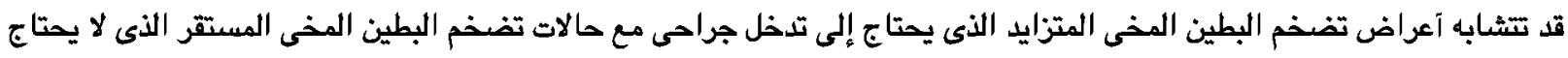

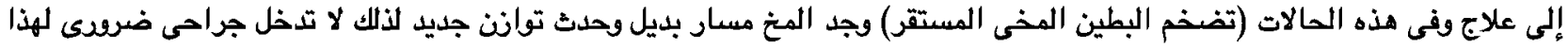

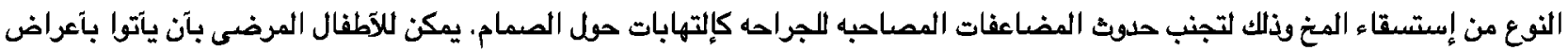

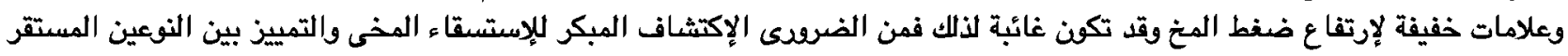
والمتزايد يعد آمرا حيويا.

وجد في بعض الآطفال التى تم تشخيصها بإستسقاء مخى مثزايد والتى إستمر عندهـ بعض من آعراض إرتفاع الضغط المخى كتآخر

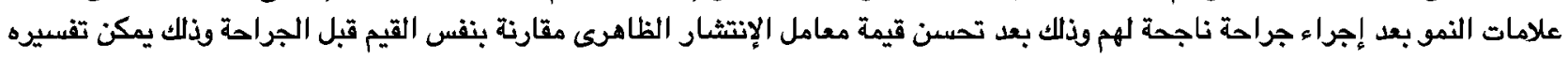

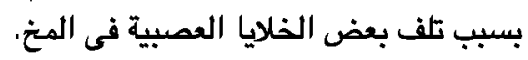

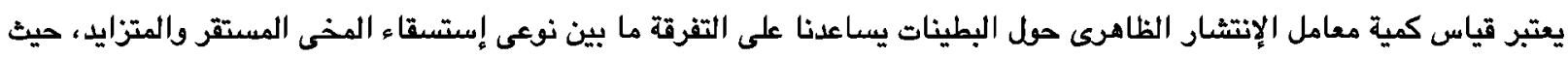

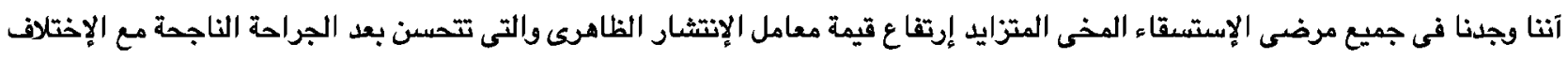
فى حالات تضخم البطين المخى المستقر وجد علم إرتفاع قيمة معامل الإنتشار الظاهرى وفى مثل هذا الحالات مزيد من المتابعات يوصى الإنى 